\title{
Fine Particle Profile of Fluticasone Propionate/ Formoterol Fumarate Versus Other Combination Products: the DIFFUSE Study
}

\author{
Baljinder Johal · Markus Howald • Manfred Fischer • \\ Jonathan Marshall • Geraldine Venthoye
}

To view enhanced content go to www.combitherapy-open.com

Received: June 24, 2013 / Published online: August 30, 2013

(c) The Author(s) 2013. This article is published with open access at Springerlink.com

\section{ABSTRACT}

Introduction: The efficacy of inhaled products is affected by the degree, and potentially the site, of drug particle deposition in the lungs. Lung deposition correlates with the fine particle fraction (FPF; the proportion of dose containing particles $<5 \mu \mathrm{m}$ in aerodynamic diameter). This in vitro study (defining fluticasone propionate/ formoterol particulate size [DIFFUSE]) examined the effects of inhalation flow rate on the FPF of the fluticasone propionate/

B. Johal $(\bowtie)$

Mundipharma Research Limited, Cambridge

Science Park, Milton Road, Cambridge CB4 0GW, UK

e-mail: baljinder.johal@mundipharma-rd.eu

M. Howald · M. Fischer - G. Venthoye

Skyepharma AG, Eptingerstrasse 61, 4132 Muttenz, Switzerland

J. Marshall

Mundipharma International Limited, 194 Science

Park, Milton Road, Cambridge CB4 OAB, UK

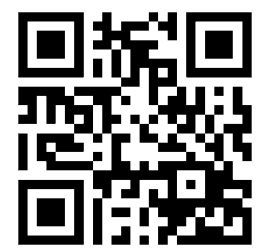

Enhanced content for this article is available on the journal web site: www.combitherapy-open.com formoterol (FP/FORM) pMDI aerosol compared with three other inhaled corticosteroids/longacting $\beta_{2}$-agonist (ICS/LABA) combination therapies administered by either DPI or pMDI [fluticasone propionate/salmeterol (FP/SAL), budesonide/formoterol (BUD/FORM) and beclometasone dipropionate/formoterol (BDP/ FORM)].

Methods: Aerodynamic particle size distribution was determined for each product using an 8-stage Andersen Cascade Impactor at two inhalation flow rates: 28.3 and $60.0 \mathrm{~L} / \mathrm{min}$. Fine particle dose (mass of dose $<5.0 \mu \mathrm{m}$ ) and FPF were calculated as a percentage of the labeled dose for the LABA and ICS of each product at both flow rates.

Results: FP/FORM suspension aerosol provided a high and consistent FPF of approximately 40\% for the ICS and LABA components at both flow rates. At $28.3 \mathrm{~L} / \mathrm{min}$, the FPF of each component of FP/FORM (41.2\% and 39.2\%) was greater than that of FP/SAL DPI (12.5\% and $11.3 \%)$, BUD/FORM DPI (8.2\% and 6.6\%) and BDP/ FORM pMDI (28.5\% and 26.0\%). At $60.0 \mathrm{~L} / \mathrm{min}$, the FPFs of the FP/FORM components $(43.7 \%$ and $42.1 \%$ ) were greater than those of $\mathrm{FP} / \mathrm{SAL}$ (17.8\% and 14.8\%) and BUD/FORM (35.0\% and 
$30.1 \%$ ), and similar to those of BDP/FORM (43.0\% and 39.5\%).

Discussion: The FP/FORM suspension aerosol produced a high and consistent FPF of approximately $40 \%$ across both flow rates. The consistent FPF in vitro may be predictive of FP/ FORM providing more consistent drug dosing in vivo, helping to counteract variable lung dose due to variation in inspiratory flow rate among patients and between a patient's day-today or successive inhalation maneuvers.

Keywords: Aerodynamic particle size distribution; Andersen Cascade Impactor; Bronchodilators; Fine particle fraction; Flow rate dependency; Inhaled corticosteroids/longacting $\beta_{2}$-agonist combination products; Pressurized metered-dose inhalers; Respiratory

\section{INTRODUCTION}

The efficacy of an inhaled drug is dependent on the propensity for drug particles to deposit throughout the lungs [1]. Deposition of drug particles in the airways is affected by several, often interrelated, factors, including the intrinsic properties of the inhaler, drug formulation and patient characteristics [2-5]. Drug formulation (i.e., dry powder or aerosol), the mechanics of drug aerosolization and dose delivery of the device [6], the particle carrier and required inhalation rate for particle deagglomeration [for dry-powder inhalers (DPIs)] [7, 8], or the characteristics of the propellant and the plume velocity [for pressurized metered-dose inhalers (pMDIs)] $[4,6,9]$, as well as the particle size distribution profile of the emitted drug, are all properties inherent to the inhaled product. Patient-related factors include anatomy, disease state, lung function and the way in which an individual uses his inhaler (i.e., device handling, inhalation maneuvers, and inhalation flow rate and volume) $[1-3,5,10-12]$.

In vitro particle size profiles of emitted particles correlate with in vivo lung deposition. Particles larger than $5 \mu \mathrm{m}$ in aerodynamic diameter are prone to being deposited in the mouth or throat, where they do not exert therapeutic effects and may increase the risk of local side effects $[5,13,14]$. Fine particles $(<5 \mu \mathrm{m})$ are associated with deposition throughout the airways [1, 4, 5, 15-18]. The proportion of an emitted aerosolized drug dose that contains fine particles is referred to as the fine particle fraction (FPF). Pharmacokinetic studies and threedimensional imaging techniques have shown that inhaled corticosteroids (ICSs) with a higher FPF are associated with greater levels of lung deposition than those with a lower FPF $[17,19]$. Imaging data have also indicated that fine particles deposit in both the large and small airways [19]. The FPF may therefore be an important attribute for an ICS and long-acting $\beta_{2}$-agonist (LABA) combination therapy (ICS/ LABA) because the pathophysiology of asthma involves both the proximal and distal airways. The ICS targets inflammation, which affects airways from the large bronchi to the alveoli, while bronchodilation is driven by $\beta_{2}$-agonists acting on smooth muscle in the proximal airways $[19,20]$. Thus, it follows that the deposition profile of an ICS/LABA combination therapy should facilitate targeting of inflammation throughout the lungs and provision of bronchodilation in the proximal airways.

The ICS fluticasone propionate (FP) and LABA formoterol fumarate (FORM) have been combined in a single, hydrofluoroalkane (HFA)based, aerosol inhaler [FP/FORM; flutiform ${ }^{\circledR}$ (Jagotec AG, Muttenz, Switzerland)]. FP/FORM has been approved for maintenance treatment of asthma in adults and adolescents at twice-daily doses of 100/10, 250/10 $\mu \mathrm{g}$ and (adults only) 
$500 / 20 \mu \mathrm{g}$ when an ICS/LABA therapy is appropriate. The efficacy and tolerability of FP/ FORM across a range of asthma severities have been demonstrated in several studies. FP/FORM has a similar efficacy and tolerability profile to those of fluticasone propionate/salmeterol xinafoate (FP/SAL; pMDI) and budesonide/ formoterol (BUD/FORM; DPI), the two most commonly prescribed ICS/LABA combinations $[21,22]$.

It is widely accepted that DPIs are often associated with flow rate-dependent changes in the FPF; this is largely because the dry-powder formulation needs to be deagglomerated into respirable drug particles, a process that is dependent, to a variable extent, on the inspiratory force at which the patient inhales through the device $[7,8,23]$. With pMDIs, drug particles, either suspended or dissolved in a cosolvent/propellant mixture (suspension or solution formulations, respectively), are aerosolized on actuation of the inhaler [6]. Therefore, it is expected that inhalation flow rate would not have a significant impact on the FPF. In this study (defining fluticasone propionate/formoterol particulate size [DIFFUSE]), the in vitro FPF profile of the FP/ FORM aerosol was compared with that of the commercially available FP/SAL and BUD/FORM DPIs. The beclometasone dipropionate (beclometasone)/formoterol (BDP/FORM) aerosol was included as a benchmark comparator.

\section{MATERIALS AND METHODS}

\section{ICS/LABA Combinations}

This study compared the aerodynamic particle size distribution (APSD) profiles of FP/FORM (pMDI) with three other single-inhaler ICS/
LABA combination products: FP/SAL [Seretide ${ }^{\circledR}$ Accuhaler $^{\circledR}$ (GlaxoOperations UK Ltd, Herts, UK); $\quad$ DPI]; $\quad$ BUD/FORM $\quad$ [Symbicort ${ }^{\circledR}$ Turbohaler $^{\circledR} \quad$ (AstraZeneca AB, Södertälje, Sweden); DPI]; and BDP/FORM [Foster ${ }^{\circledR}$ (Chiesi Farmaceutici S.p.A, Parma, Italy); HFA pMDI]. Drug strengths were selected based on their ability to deliver similar treatment doses (Table 1).

\section{Aerodynamic Particle Size Distribution Profiles}

APSD tests were performed using the Apparatus D 8-stage Andersen Cascade Impactor (ACI; Copley Scientific Limited, Nottingham, UK), with an induction port and pre-separator for powder formulations, according to the European Pharmacopoeia 7.8, General Chapter 2.9.18: 'Preparations for inhalations, aerodynamic assessment of fine particles'. Testing was performed at room temperature under ambient humidity conditions. To ensure thermal re-equilibration of the valve, pMDIs were actuated four times with a delay of approximately $2 \mathrm{~s}$ between each actuation. For the DPI testing, the plates of the ACI were coated with a surfactant $\left(\right.$ Tween $^{\circledR} 20$; Croda France, Trappes Cedex, France) to avoid potential bouncing or re-entrainment effects; a pressure drop ( $4 \mathrm{kPa}$ ) was included at the start of the 'inhalation', as recommended for quality testing (to simulate the sharp initiation inhalation recommended for DPIs). APSD profiles were assessed at inhalation flow rates of 28.3 and $60.0 \mathrm{~L} / \mathrm{min}$, which are within the clinically effective range of flow rates for the inhalers tested, and are consistent with industry standards for the quality control testing of inhaled medicines. Five inhalers were tested for each product. The cumulative drug mass recovered from the ACI following each test was 
Table 1 Summary of the ICS/LABA combinations tested

\begin{tabular}{|c|c|c|c|c|}
\hline ICS/LABA & Inhaler type & $\begin{array}{l}\text { Dose strength tested } \\
\text { (single actuation) }(\mu \mathrm{g})\end{array}$ & $\begin{array}{l}\text { Comparable } \\
\text { treatment dose }(\mu \mathrm{g})\end{array}$ & $\begin{array}{l}\text { Actuations used to } \\
\text { deliver treatment dose }\end{array}$ \\
\hline \multicolumn{5}{|l|}{ FP/FORM } \\
\hline Batch number AA11023 & pMDI & $125 / 5$ & $250 / 10$ & 2 \\
\hline \multicolumn{5}{|l|}{$\mathrm{FP} / \mathrm{SAL}^{\mathrm{a}}$} \\
\hline Batch number R502221 & DPI & $250 / 50$ & $250 / 50$ & 1 \\
\hline \multicolumn{5}{|l|}{$\mathrm{BUD} / \mathrm{FORM}^{\mathrm{b}}$} \\
\hline Batch number NA3626 & DPI & $200 / 6$ & $400 / 12$ & 2 \\
\hline \multicolumn{5}{|l|}{$\mathrm{BDP} / \mathrm{FORM}^{\mathrm{c}}$} \\
\hline Batch number 109215 & pMDI & $100 / 6$ & $200 / 12$ & 2 \\
\hline
\end{tabular}

normalized to the labeled dose for each combination component at both flow rates tested.

\section{Fine Particle Fraction}

The fine particle dose (mass of dose comprising particles $<5.0 \mu \mathrm{m}$ ) was interpolated from the cumulative distribution for the ACI stages, with cutoff diameters of 3.3, 4.7 and $5.8 \mu \mathrm{m}$, and normalized for the labeled dose. The FPF was calculated as a percentage of the labeled dose for the ICS and for the LABA component of each product, at both flow rates. The ratio between FPFs at 60.0 and $28.3 \mathrm{~L} / \mathrm{min}$ (FPF 60.0/28.3) for both the ICS and LABA component of each ICS/ LABA combination tested was also calculated.

\section{Median Mass Aerodynamic Diameter}

The median mass aerodynamic diameter (MMAD) was derived from inertial impaction data, assuming a log-normal dispersion of sizes, according to ISO 27427 'Anaesthetic and respiratory equipment-nebulising systems and components'. The geometric standard deviation was calculated from the particle size at the 84 th percentile (by mass) divided by the MMAD.

\section{Statistical Analysis}

The objectives of the study were: (1) to quantify the effect of flow rate on the FPF for each of the four products and (2) to compare the FPF of the comparator products to that of the FP/FORM pMDI at each of the studied flow rates. Results from one inhaler (\#3, Seretide batch R502221) tested at $28.3 \mathrm{~L} / \mathrm{min}$ were atypical and removed from statistical analysis.

The FPF data were normalized to the target metered dose to compare the products. Both objectives were investigated by means of standard equivalence testing; a 90\% confidence interval (CI) for the mean TEST/ REFERENCE ratio was determined based on logtransformed FPF data, and equivalence was concluded if the CI was contained in the 
0.85-1.18 $( \pm 15 \%) \quad$ acceptance interval recommended by the European Medicines Agency for in vitro equivalence. For objective (1) the reference was $60 \mathrm{~L} / \mathrm{min}$, and for objective (2) the reference was FP/FORM. The same analysis was performed independently for both drug components. Means and standard deviations are presented for each product; API and flow rate were calculated in original scale (not using the log transformation).

This article does not contain any studies of human subjects performed by any of the authors.

\section{RESULTS}

\section{Fine Particle Fraction}

FP/FORM produced a high FPF of approximately $40 \%$ for both the ICS and the LABA components at flow rates of 28.3 and $60.0 \mathrm{~L} / \mathrm{min}$ (Fig. 1). The FPF of FP/FORM was significantly higher than that of the FP/SAL and BUD/FORM DPIs (Table 2; Fig. 1). The FP/SAL DPI produced an FPF of less than $20 \%$ for each component at both flow rates, while the FPF of budesonide for the BUD/FORM DPI was $8.2 \%$ at $28.3 \mathrm{~L} / \mathrm{min}$ and $35.0 \%$ at $60.0 \mathrm{~L} / \mathrm{min}$.

The FPF of FP/FORM was consistent across the flow rates tested, as shown by the FPF 60.0/ 28.3 ratios of 1.06 for fluticasone and 1.08 for formoterol (Table 2), which were within the specified acceptance interval for equivalence. By contrast, the FPFs emitted from the FP/SAL and BUD/FORM DPIs demonstrated marked flow rate dependency. The FPF 60.0/28.3 ratio for the FP/SAL DPI was 1.43 for fluticasone and 1.33 for salmeterol (Table 2). Similarly, the FPF of BUD/FORM increased more than fourfold for the ICS and LABA components between the lower and higher flow rates (Fig. 1), with FPF
$60.0 / 28.3$ ratios of 4.38 for budesonide and 4.63 for formoterol (Table 2).

The FPF of BDP/FORM at $28.3 \mathrm{~L} / \mathrm{min}$ was less than $30 \%$. The BDP/FORM FPF varied with flow rate and was approximately $40 \%$ at $60.0 \mathrm{~L} / \mathrm{min}$ (Fig. 1; Table 2). The variation in the FPF across flow rates was demonstrated by the 60.0/28.3 ratios of 1.51 for beclometasone and 1.52 for formoterol (Table 2).

\section{Aerodynamic Particle Size Distribution Profiles and Median Mass Aerodynamic Diameters}

APSD profiles and MMADs were relatively similar for the ICS and LABA components of each combination tested, at both flow rates, indicating consistency between component particle size fractions (Table 3). FP/FORM showed a similar cumulative particle fraction distribution profile and MMAD at both 28.3 and 60.0 L/min, consistent with the similar FPFs observed between flow rates (Fig. 2a; Table 3). The APSD profile of FP/SAL was shallow at both 28.3 and $60.0 \mathrm{~L} / \mathrm{min}$, with particles distributed across a broad range of sizes (Fig. 2b); there was relative inconsistency in both the FPF and the MMAD between the flow rates (Tables 2, 3). For $\mathrm{BUD} / \mathrm{FORM}$, the APSD profile and MMAD were both noticeably different at $28.3 \mathrm{~L} / \mathrm{min}$ and at $60.0 \mathrm{~L} / \mathrm{min}$, with an increased mass of particles in the range $1.1-10.0 \mu \mathrm{m}$ at $60.0 \mathrm{~L} / \mathrm{min}$ (Fig. 2c; Table 3).

BDP/FORM also showed flow rate-dependent effects for the cumulative particle fraction (Fig. 2d), with a shift in the profile from 28.3 to $60.0 \mathrm{~L} / \mathrm{min}$ and an increased mass of particles smaller than $1.1 \mu \mathrm{m}$ at the higher flow rate, resulting in a decrease in the MMAD from $1.21 \mu \mathrm{m}$ and $1.24 \mu \mathrm{m}$ for ICS and LABA, respectively, at $28.3 \mathrm{~L} / \mathrm{min}$, to 0.50 and $0.49 \mu \mathrm{m}$ at $60.0 \mathrm{~L} / \mathrm{min}$ (Table 3). 

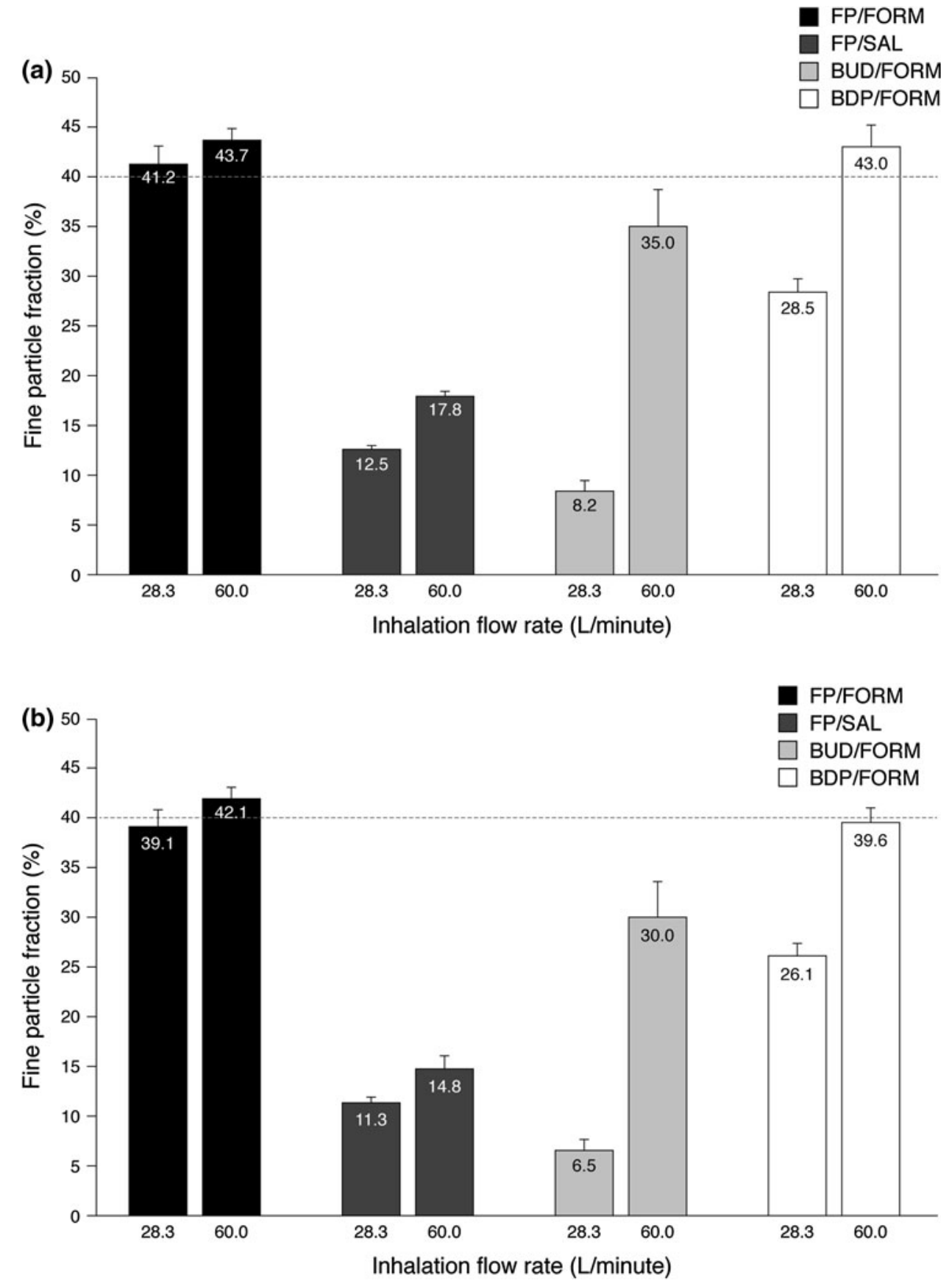

Fig. 1 FPFs of the $\mathbf{a}$ ICS and $\mathbf{b}$ LABA components of the combination therapies at 28.3 and $60.0 \mathrm{~L} / \mathrm{min}$. Error bars represent standard error. $C I$ confidence interval, FPF fine

\section{DISCUSSION}

The primary aim of this in vitro study was to characterize the FPF of the FP/FORM inhalation particle fraction, ICS inhaled corticosteroid, LABA longacting $\beta_{2}$-agonist

aerosol relative to those of the two most widely prescribed ICS/LABA DPIs at two different inhalation flow rates that are achievable by patients using both DPI and pMDIs, and that 
Table 2 Ratios and 90\% CIs of the FPFs for the ICS and LABA components of each combination versus those of FP/ FORM

\begin{tabular}{|c|c|c|c|}
\hline ICS/LABA & $\begin{array}{l}\text { Ratio versus } \\
\text { FP/FORM }(90 \% \mathrm{CI})^{\mathrm{a}} \\
28.3 \mathrm{~L} / \mathrm{min}\end{array}$ & $\begin{array}{l}\text { Ratio versus } \\
\text { FP/FORM }(90 \% \mathrm{CI})^{\mathrm{a}} \\
60.0 \mathrm{~L} / \mathrm{min}\end{array}$ & $\begin{array}{l}\text { Ratio of flow } \\
\text { rates }(90 \% \mathrm{CI})^{\mathrm{b}}\end{array}$ \\
\hline \multicolumn{4}{|l|}{ ICS component } \\
\hline FP/FORM (FP) & - & - & $1.06(1.02,1.10)$ \\
\hline FP/SAL (FP) & $0.30(0.28,0.32)^{*}$ & $0.41(0.40,0.41)^{*}$ & $1.43(1.36,1.51)$ \\
\hline BUD/FORM (BUD) & $0.20(0.18,0.22)^{*}$ & $0.80(0.73,0.86)^{*}$ & $4.38(3.71,5.04)$ \\
\hline BDP/FORM (BDP) & $0.69(0.66,0.73)^{*}$ & $0.98(0.95,1.02)$ & $1.51(1.47,1.55)$ \\
\hline \multicolumn{4}{|l|}{ LABA component } \\
\hline FP/FORM (FORM) & - & - & $1.08(1.04,1.11)$ \\
\hline FP/SAL (SAL) & $0.29(0.28,0.31)^{*}$ & $0.35(0.34,0.37)^{*}$ & $1.33(1.20,1.45)$ \\
\hline BUD/FORM (FORM) & $0.17(0.15,0.19)^{*}$ & $0.71(0.65,0.78)^{*}$ & $4.63(3.92,5.33)$ \\
\hline BDP/FORM (FORM) & $0.66(0.63,0.70)^{*}$ & $0.94(0.92,0.96)^{*}$ & $1.52(1.47,1.57)$ \\
\hline
\end{tabular}

$B D P$ beclometasone dipropionate, $B U D$ budesonide, $C I$ confidence interval, $F P$ fluticasone propionate, FORM formoterol fumarate, $F P F$ fine particle fraction, ICS inhaled corticosteroid, $L A B A$ long-acting $\beta_{2}$-agonist, $S A L$ salmeterol xinafoate

* Indicates statistical difference at the $P<0.1$ level versus $\mathrm{FP} / \mathrm{FORM}$

${ }^{a}$ Ratio $(90 \% \mathrm{CI})$ of FPF versus FP/FORM

${ }^{b}$ Ratio $(90 \% \mathrm{CI})$ of FPF at 28.3 versus $60 \mathrm{~L} / \mathrm{min}$

are considered to deliver clinically effective doses for these device types. The BDP/FORM aerosol was originally included as a benchmark pMDI in this study. FP/FORM produced a high (approximately 40\%) and consistent FPF at 28.3 and $60.0 \mathrm{~L} / \mathrm{min}$, which was greater than the FPF of FP/SAL and BUD/FORM. By contrast, the FPF varied across flow rates for both DPIs. For the FP/SAL DPI, there was a $5.3 \%$ absolute increase (42\% relative increase) in ICS FPF and a 3.5\% absolute increase (31\% relative increase) in LABA FPF when the flow rate increased from 28.3 to $60.0 \mathrm{~L} / \mathrm{min}$. For the BUD/FORM DPI, the difference in FPF between flow rates was greater: an absolute increase of $26.8 \%$ (327\% relative increase) in ICS FPF and a $23.5 \%$ absolute increase (356\% relative increase) in LABA FPF were observed when the flow rate was increased from 28.3 to $60.0 \mathrm{~L} / \mathrm{min}$. These findings are consistent with those of previous in vitro investigations $[8,23,24]$ and are largely due to the inspiratory force required to deagglomerate and aerosolize the drug dose during inhalation with a DPI. The similarity of the drug mass ratios for each size fraction, for all products tested, demonstrated that ICS and LABA particles generated during the atomization process are consistent in size or are coassociated, and would therefore be expected to co-deposit in the airways. This finding is in line with those of previous studies [25].

Given that MMAD and FPF are interrelated, it was unsurprising that the consistent FPF of FP/FORM correlated with MMAD at both flow rates. In contrast, both DPIs produced higher MMADs at the lower flow rate, which also 
Table 3 MMADs for the ICS and LABA components of each combination tested at 28.3 and $60.0 \mathrm{~L} / \mathrm{min}$

\begin{tabular}{|c|c|c|}
\hline ICS/LABA & $\begin{array}{l}\text { Flow rate } \\
28.3 \mathrm{~L} / \mathrm{min} \\
\text { MMAD } \pm \text { GSD } \\
(\mu \mathrm{m})\end{array}$ & $\begin{array}{l}\text { Flow rate } \\
60.0 \mathrm{~L} / \mathrm{min} \\
\text { MMAD } \pm \mathrm{GS} \\
(\mu \mathrm{m})\end{array}$ \\
\hline \multicolumn{3}{|l|}{ ICS component } \\
\hline FP/FORM (FP) & $3.52 \pm 1.59$ & $3.15 \pm 1.77$ \\
\hline FP/SAL (FP) & $4.65 \pm 1.66$ & $3.72 \pm 1.83$ \\
\hline $\begin{array}{l}\text { BUD/FORM } \\
\text { (BUD) }\end{array}$ & $3.77 \pm 1.94$ & $2.49 \pm 1.91$ \\
\hline $\begin{array}{l}\text { BDP/FORM } \\
\text { (BDP) }\end{array}$ & $1.21 \pm 2.77$ & $0.50 \pm 4.46$ \\
\hline \multicolumn{3}{|l|}{ LABA component } \\
\hline $\begin{array}{l}\text { FP/FORM } \\
\text { (FORM) }\end{array}$ & $3.52 \pm 1.56$ & $3.17 \pm 1.71$ \\
\hline FP/SAL (SAL) & $4.89 \pm 1.86$ & $3.97 \pm 1.96$ \\
\hline $\begin{array}{l}\text { BUD/FORM } \\
\text { (FORM) }\end{array}$ & $3.77 \pm 1.92$ & $2.53 \pm 1.89$ \\
\hline $\begin{array}{l}\text { BDP/FORM } \\
\text { (FORM) }\end{array}$ & $1.24 \pm 2.87$ & $0.49 \pm 5.33$ \\
\hline
\end{tabular}

$B D P$ beclometasone dipropionate, $B U D$ budesonide, $F P$ fluticasone propionate, FORM formoterol fumarate, GSD, geometric standard deviation; ICS inhaled corticosteroid, $L A B A$ long-acting $\beta_{2}$-agonist, MMAD median mass aerodynamic diameter, $S A L$ salmeterol xinafoate

varied considerably with increasing flow rate. The FP/SAL DPI was associated with relatively large particles (correlating with the flat APSD profile), with an MMAD of $4.89 \mu \mathrm{m}$ for the LABA component at the lower flow rate. The BUD/FORM DPI produced an MMAD of $3.77 \mu \mathrm{m}$ for the LABA component at the lower flow rate. These data indicate that at the lower flow rate, a large proportion of the dose of FP/SAL is emitted as particles larger than $5 \mu \mathrm{m}$; particles of this size are known to be more prone to being deposited in the mouth and throat than fine particles [5]. This increased risk of oropharyngeal deposition may be associated with local adverse effects $[13,14]$. As expected, the magnitude of the flow rate effect on MMAD was greater for BUD/FORM than for $\mathrm{FP} / \mathrm{SAL}$, with a shift in MMAD from approximately $3.8 \mu \mathrm{m}$ (at $28.3 \mathrm{~L} / \mathrm{min}$ ) to approximately $2.5 \mu \mathrm{m}$ (at $60.0 \mathrm{~L} / \mathrm{min}$ ) for both the LABA and ICS components. These findings highlight that there is greater potential for deposition of large particles in the mouth and throat, rather than in the airways, at a lower inhalation flow rate for both DPIs compared with the pMDIs tested in this study.

Data on the FPF for BDP/FORM have been reported previously by Lewis and colleagues [25] as a proportion of the delivered dose at a flow rate of $28.3 \mathrm{~L} / \mathrm{min}$. In the present study, FPFs were calculated as a proportion of the labeled dose, and the FPF for the LABA component of BDP/FORM was $26.0 \%$ at $28.3 \mathrm{~L} / \mathrm{min}$. When the data reported by Lewis and colleagues were recalculated as a proportion of the labeled dose, rather than the delivered dose, the FPF for the LABA component of BDP/FORM was $31.6 \%$, which is comparable to the finding of the present study. In addition, the MMAD values calculated in the present study for BDP/FORM were similar to those reported by Lewis and colleagues $(1.21 \mu \mathrm{m}$ for the ICS and $1.24 \mu \mathrm{m}$ for the LABA in the present study, versus 1.4 and $1.5 \mu \mathrm{m}$, respectively, as reported by Lewis). The aerosolized drug emitted from a pMDI is influenced by the propellant and the characteristics of the inhaler and, unlike DPIs, is not dependent on inspiratory force to deagglomerate the drug. This can lead to the perception that the FPF generated with pMDIs is also not dependent on inhalation flow rate. However, when flow rate increased from 28.3 to $60.0 \mathrm{~L} / \mathrm{min}$, there was an increase in the $\mathrm{BDP} /$ FORM FPF (formoterol component, from $26.0 \%$ to $39.5 \%)$. Similar to the findings for both DPIs, the flow rate dependency of the BDP/FORM FPF 
(a)

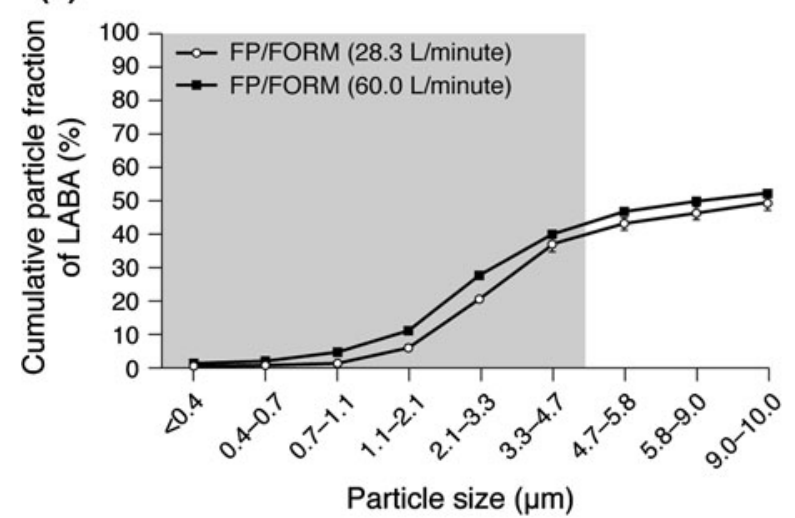

(c)

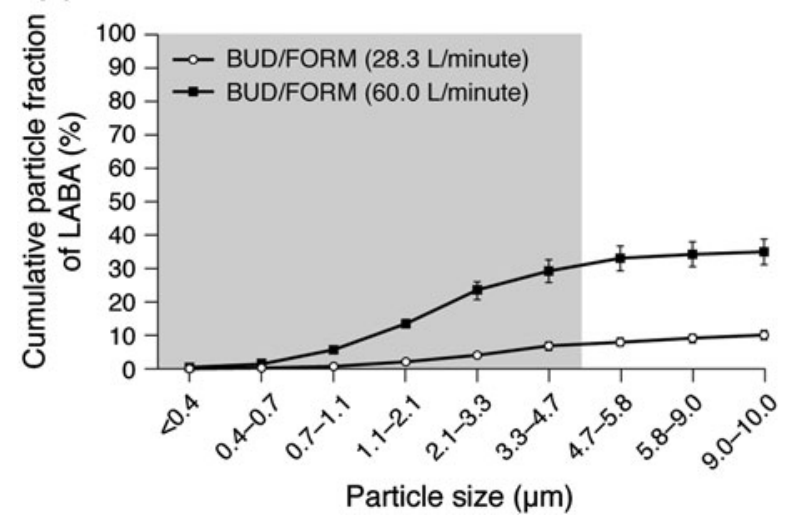

Fig. 2 Aerodynamic particle size distribution profiles of the LABA component for a FP/FORM, b FP/SAL, c BUD/FORM and d BDP/FORM. Error bars represent standard error. Cumulative drug masses recovered from the

correlated with a lower MMAD at the $60.0 \mathrm{~L} /$ min flow rate (from $1.21 \mu \mathrm{m}$ at $28.3 \mathrm{~L} / \mathrm{min}$ to $0.50 \mu \mathrm{m}$ at $60.0 \mathrm{~L} / \mathrm{min}$ for the ICS), demonstrating the shift toward much smaller particles with increasing flow rate.

The cause of the observed effect of flow rate on BDP/FORM is not understood fully and we are not aware of any published data reporting the APSD profile of the BDP/FORM aerosol at $60.0 \mathrm{~L} / \mathrm{min}$ or higher. Environmental and experimental factors, such as humidity and temperature, can influence aerosolized drug characteristics in vitro [26]. All products tested in the present study, however, were subject to the same environmental and experimental (b)

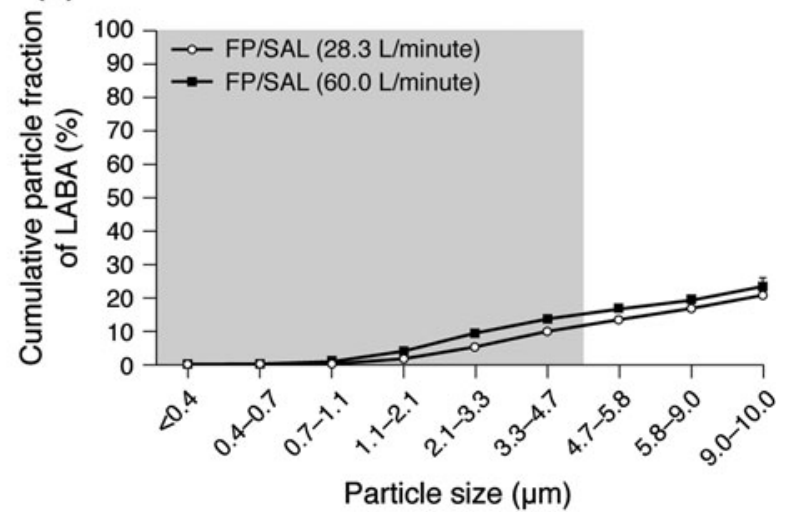

(d)

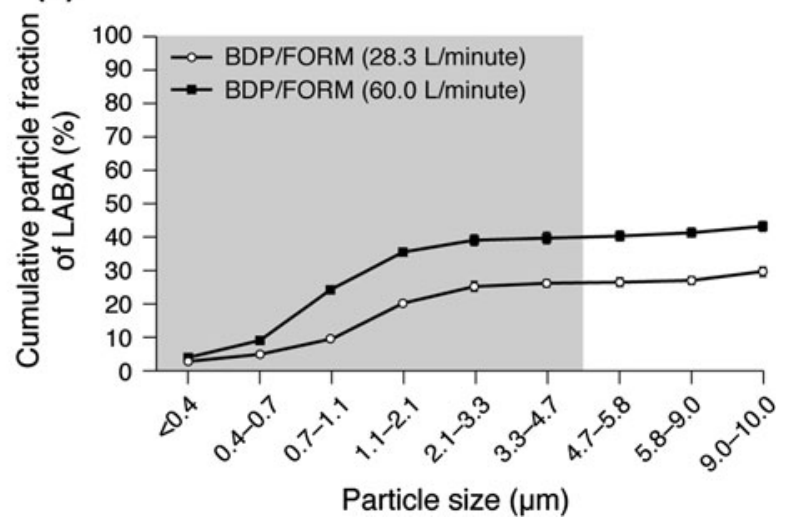

ACI normalized for labeled dose are shown at 28.3 and $60.0 \mathrm{~L} / \mathrm{min}$. $A C I$ Andersen Cascade Impactor, ICS inhaled corticosteroid, $L A B A$ long-acting $\beta_{2}$-agonist

parameters, with only flow rate as a variable. Given that both combinations were analyzed under identical conditions and in accordance with the European Pharmacopoeia methodology, it is highly likely that the observed results relate to an effect of flow rate. There is support for this from a previous study, which demonstrated that the in vitro performance of some ICS/LABAs can be affected by flow rate, leading to increased deposition of particles in the 'throat' of the apparatus at low flow rates [27]. Such variance in FPF could be attributed to several factors, including turbulence (created as the aerosol is generated owing to the velocity difference of 
the impactor air flow and the aerosol plume) and droplet particle evaporation, which result in changes to particle deposition in the impactor throat $[28,29]$. Flow rate had little effect on fluticasone/formoterol, but a greater impact on beclometasone/formoterol; hence, the observed flow rate-dependent effects probably relate to differences in the formulations of the two products. There are several differences between the composition of the FP/FORM and the BDP/FORM aerosols, and their respective devices: FP/FORM is a suspension containing the propellant, apaflurane (HFA-227), whereas BDP/FORM is a solution and contains the propellant norflurane (HFA-134a). Furthermore, there are differences in alcohol content (FP/FORM: $1 \mathrm{mg} /$ actuation; BDP/FORM: $7 \mathrm{mg} /$ actuation) and other excipients (FP/FORM: sodium cromoglycate; BDP/FORM: hydrochloric acid). Interestingly, a similar flow rate-dependent effect has been noted for an HFA-based, solution formulation of beclometasone, which has a similar alcohol content to that of the BDP/FORM product tested in this study (8.35 mg/actuation) [24, 27].

Although an optimal particle size for ICS/ LABA therapy has not yet been determined [30], it is known that large particles $(>5 \mu \mathrm{m})$ are more prone to being deposited in the throat and mouth, and that very small extra-fine particles (0.1-1.0 $\mu \mathrm{m}$; those that deposit via diffusion and sedimentation) are prone to exhalation, especially if the breath-hold is insufficient. The observation that the BDP/FORM aerosol generated an MMAD of approximately $0.50 \mu \mathrm{m}$ (for the ICS component) at a flow rate of $60.0 \mathrm{~L} /$ min may therefore have in vivo implications, because at the higher flow rate there may be increased potential for particle exhalation; however, particle size distribution around the MMAD has a greater influence on drug deposition throughout the lungs than any specific MMAD value [1, 31]. Evidence suggests that fine particles in the range $2-5 \mu \mathrm{m}$ may be a suitable size for distribution of an ICS/LABA throughout the lungs [18]. Indeed, in vivo imaging techniques have shown that particles in this size range deposit in both the large and small airways [19]. In asthma, the large and small airways associated with bronchoconstriction and inflammation must be treated [18]. A significant proportion of the emitted FP/FORM dose, at both 28.3 and $60.0 \mathrm{~L} /$ min, falls in this size range $(2-5 \mu \mathrm{m})$, which may facilitate drug deposition throughout the airways.

As with any in vitro investigation, caution must be applied when translating findings to the in vivo setting [1]; however, the European Pharmacopoeia methodology used in this study is well established and can be used to predict the behavior of drug particles in the human respiratory tract [1]. In addition to the properties inherent to the inhaler and the drug formulation, a patient's inspiratory maneuvers will also affect the potential for deposition of the drug in the airways. Patients often make errors when taking their ICS/LABA, emphasizing the need for regular training and inhaler-use assessments [32]. Furthermore, a patient's inhalation flow rate is not constant during an inhalation maneuver and may vary from breath to breath, and therefore from dose to dose; the flow rate may also vary from patient to patient [24, 33]. Inhalation flow rate impacts significantly on total and regional patterns of deposition of drug particles in the airways [19]. Therefore, an ICS/LABA with a relatively flow rate independent, consistent FPF might facilitate more uniform dosing in the lungs, compensating for variations in inspiratory flow rates among patients, and variations in patients' day-to-day or successive inhalation maneuvers. 
In 12-week, randomized clinical trials, $\mathrm{FP} /$ FORM has a similar efficacy and tolerability profile to $\mathrm{FP} / \mathrm{SAL}$ pMDI (in patients $\geq 18$ years with $125 / 5$ and $50 / 5 \mu \mathrm{g}$ FP/FORM doses) and BUD/FORM DPI (in patients $\geq 12$ years with 125/5 $\mu$ g FP/FORM dose) [21, 22]. Patients need to demonstrate optimal inhalation maneuvers and undergo repeated training to maintain their inhaler technique for inclusion in such studies; hence, it would be unlikely that a difference between two inhalers would be observed. There is, however, evidence to suggest that some modern HFA-based pMDIs, which have greater FPFs than current DPIs and the discontinued chlorofluorocarbon (CFC)-based pMDIs, may provide better control of asthma symptoms. A recent retrospective, observational study compared asthma outcomes in 3,134 patients who were receiving $\mathrm{FP} / \mathrm{SAL}$, administered via either a DPI or a pMDI. The findings of this study demonstrated that in practice, patients using a pMDI achieved better asthma control than those using a DPI [34]. The authors suggested that these results could reflect differences in FPF between the pMDI and DPI formulations of FP/ SAL. Notably, the FPF of the FP/SAL DPI in the present study is markedly lower than that previously reported for the pMDI formulation (30-33\%, as percentage of the metered dose), when assessed using an ACI without a spacer, as per the present study $[35,36]$. Similarly, an HFAbased formulation of beclometasone provided better asthma outcomes than a CFC-based version in another observational study. Improved asthma control with the HFA-based formulation may be related to the higher FPF.

\section{CONCLUSION}

In conclusion, in vitro FP/FORM emits a high and consistent FPF (approximately 40\%) at
28.3 and $60.0 \mathrm{~L} / \mathrm{min}$. The FPF of FP/FORM was less affected by changes in flow rate than the other products tested. Consistent FPFs may be associated with potential in vivo benefits.

\section{ACKNOWLEDGMENTS}

Baljinder Johal is the guarantor for this article and takes responsibility for the integrity of the work as a whole. The authors would like to thank Ruben Lüthi, Magali Simet, Nicole Wegner and Christine Schwendener-Holzer (Skyepharma AG, Muttenz, Switzerland) who participated in this study, colleagues at Mundipharma Research Limited and Skyepharma AG, and Colin Griffin of Oxford PharmaGenesis ${ }^{\mathrm{TM}}$ Ltd, who provided editorial support on behalf of Mundipharma International Limited. This study was sponsored by Mundipharma Research Limited. Data were produced by Skyepharma AG, Muttenz, Switzerland, and analyzed by Mundipharma Research Limited and Mundipharma International Limited, Cambridge, UK. Sponsorship and article processing charges for this study were funded by Mundipharma Research Limited.

Conflict of interest. B Johal is an employee of Mundipharma Research Limited, J Marshall an employee of Mundipharma International Limited, $M$ Howald an employee of Skyepharma AG, M Fischer an employee of Skyepharma AG and G Venthoye an employee of Skyepharma AG.

Ethical Standards. This article does not contain any studies of human subjects performed by any of the authors. 
Open Access. This article is distributed under the terms of the Creative Commons Attribution Noncommercial License which permits any noncommercial use, distribution, and reproduction in any medium, provided the original author(s) and the source are credited.

\section{REFERENCES}

1. Heyder J. Deposition of inhaled particles in the human respiratory tract and consequences for regional targeting in respiratory drug delivery. Proc Am Thorac Soc. 2004;1:315-20.

2. Chrystyn H. Effects of device design on patient compliance: comparing the same drug in different devices. Respir Drug Deliv Eur. 2009;1:105-116.

3. Haughney J, Price D, Barnes NC, Virchow JC, Roche $\mathrm{N}$, Chrystyn $\mathrm{H}$. Choosing inhaler devices for people with asthma: current knowledge and outstanding research needs. Respir Med. 2010;104:1237-45.

4. Newman SP. Aerosol deposition considerations in inhalation therapy. Chest. 1985;88:152S-60S.

5. Newman SP, Chan HK. In vitro/in vivo comparisons in pulmonary drug delivery. J Aerosol Med Pulm Drug Deliv. 2008;21:77-84.

6. Ganderton D, Lewis D, Davies R, Meakin B, Brambilla G, Church T. Modulite: a means of designing the aerosols generated by pressurized metered dose inhalers. Respir Med. 2002;96(Suppl D):S3-8.

7. Telko MJ, Hickey AJ. Dry powder inhaler formulation. Respir Care. 2005;50:1209-27.

8. Taylor A, Gustafsson P. Do all dry powder inhalers show the same pharmaceutical performance? Int J Clin Pract Suppl. 2005;59:7-12.

9. Labiris NR, Dolovich MB. Pulmonary drug delivery. Part II: the role of inhalant delivery devices and drug formulations in therapeutic effectiveness of aerosolized medications. Br J Clin Pharmacol. 2003;56:600-12.

10. Borgström L, Asking L, Lipniunas P. An in vivo and in vitro comparison of two powder inhalers following storage at hot/humid conditions. J Aerosol Med. 2005;18:304-10.

11. Borgström L, Olsson B, Thorsson L. Degree of throat deposition can explain the variability in lung deposition of inhaled drugs. J Aerosol Med. 2006;19:473-83.

12. Heyder J, Gebhart J, Rudolf G, Schiller CF, Stahlhofen W. Deposition of particles in the human respiratory tract in the size range 0.005-15 $\mu \mathrm{m}$. J Aerosol Sci. 1986;17:811-25.

13. Mitchell JP, Nagel MW. Particle size analysis of aerosols from medicinal inhalers. KONA-Particle and Particle. 2004;22:32-65.

14. Pritchard JN. The influence of lung deposition on clinical response. J Aerosol Med. 2001;14(Suppl 1):S19-26.

15. Dolovich M, Labiris R. Imaging drug delivery and drug responses in the lung. Proc Am Thorac Soc. 2004; $1: 329-37$.

16. Leach CL. Improved delivery of inhaled steroids to the large and small airways. Respir Med. 1998;92(Suppl A):3-8.

17. Leach CL, Davidson PJ, Boudreau RJ. Improved airway targeting with the CFC-free HFAbeclomethasone metered-dose inhaler compared with CFC-beclomethasone. Eur Respir J. 1998;12:1346-53.

18. Laube BL, Janssens HM, de Jongh FH, et al. What the pulmonary specialist should know about the new inhalation therapies. Eur Respir J. 2011;37:1308-417.

19. Usmani OS, Biddiscombe MF, Barnes PJ. Regional lung deposition and bronchodilator response as a function of beta $a_{2}$-agonist particle size. Am J Respir Crit Care Med. 2005;172:1497-504.

20. Tulic MK, Christodoulopoulos P, Hamid Q. Small airway inflammation in asthma. Respir Res. 2001;2:333-9.

21. Bodzenta-Lukaszyk A, Buhl R, Balint B, Lomax M, Spooner K, Dissanayake S. Fluticasone/formoterol combination therapy versus budesonide/formoterol for the treatment of asthma: a randomized, controlled, non-inferiority trial of efficacy and safety. J Asthma. 2012;49:1060-70.

22. Bodzenta-Lukaszyk A, Dymek A, McAulay K, Mansikka H. Fluticasone/formoterol combination therapy is as effective as fluticasone/salmeterol in the treatment of asthma, but has a more rapid onset of action: an open-label, randomized study. BMC Pulm Med. 2011;11:28.

23. Hill LS, Slater AL. A comparison of the performance of two modern multidose dry powder asthma inhalers. Respir Med. 1998;92:105-10. 
24. Kamin WE, Genz T, Roeder S, et al. Mass output and particle size distribution of glucocorticosteroids emitted from different inhalation devices depending on various inspiratory parameters. J Aerosol Med. 2002;15:65-73.

25. Lewis D, Brambilla G, Church T. BDP and formoterol association within a combination HFA solution MDI. Respir Drug Deliv. 2006;3:939-42.

26. Shemirani FM, Hoe $S$, Lewis D, Church T, Vehring $\mathrm{R}$, Finlay WH. In vitro investigation of the effect of ambient humidity on regional delivered dose with solution and suspension MDIs. J Aerosol Med Pulm Drug Deliv. 2013;26:215-22.

27. Stein S, Gabrio B. Understanding throat deposition during cascade impactor testing. Respir Drug Deliv. 2000;VII:287-90.

28. Michael Y, Chowdhry BZ, Ashurst IC, Snowden MJ, Davies-Cutting C, Gray S. The physico-chemical properties of salmeterol and fluticasone propionate in different solvent environments. Int J Pharm. 2000;200:279-88.

29. Young PM, Price R, Jones S, Billings M-P. Investigation into drug and excipient interaction in dry powder inhaler combination products. Respir Drug Deliv IX. 2004;3:749-752.

30. Carvalho TC, Peters JI, Williams RO 3rd. Influence of particle size on regional lung deposition-what evidence is there? Int J Pharm. 2011;406:1-10.
31. Finlay WH. Fine particle fraction as a measure of mass depositing in the lung during inhalation of nearly isotonic nebulized aerosols. J Aerosol Sci. 1997;28:1301-9.

32. Price D, Bosnic-Anticevich S, Briggs A, et al. Inhaler competence in asthma: common errors, barriers to use and recommended solutions. Respir Med. 2012;107:37-46.

33. Burnell PKP, Malton A, Reavill K, Ball MHE. Design, validation and initial testing of the electronic lung $^{\mathrm{TM}}$ device. J Aerosol Sci. 1998;29:1011-25.

34. Price D, Roche N, Virchow JC, et al. Device type and real-world effectiveness of asthma combination therapy: an observational study. Respir Med. 2011;105:1457-66.

35. Nagel MW, Wiersema KJ, Bates SL, Mitchell JP. Performance of large- and small-volume valved holding chambers with a new combination long-term bronchodilator/anti-inflammatory formulation delivered by pressurized metered dose inhaler. J Aerosol Med. 2002;15:427-33.

36. Clearie KL, Williamson PA, Vaidyanathan S, et al. Disconnect between standardized field-based testing and mannitol challenge in Scottish elite swimmers. Clin Exp Allergy. 2010;40:731-7. 